\title{
Cholelithiasis with epigastric hernia in down's syndrome: a case report
}

\author{
Jeevan Kankaria, Santosh Madagond*
}

Department of General Surgery, SMS Medical College Jaipur, Rajasthan, India

Received: 19 January 2022

Revised: 08 February 2022

Accepted: 16 February 2022

\section{*Correspondence:}

Dr. Santosh Madagond,

E-mail: santoshmadagond@gmail.com

Copyright: (C) the author(s), publisher and licensee Medip Academy. This is an open-access article distributed under the terms of the Creative Commons Attribution Non-Commercial License, which permits unrestricted non-commercial use, distribution, and reproduction in any medium, provided the original work is properly cited.

\begin{abstract}
Down's syndrome is associated with various congenital anomalies, musculoskeletal abnormalities and also various anatomical variation in organ systems. In this report we are presenting a case of cholelithiasis with Epigastric hernia in 42 years Male down's syndrome patient, on laparoscopic exploration found multiple rectus sheath defects in epigastric region and Moynihan hump. A rare case of Down's syndrome with multiple anterior abdominal wall defects.
\end{abstract}

Keywords: Down's syndrome, Cholelithiasis, Moynihan hump, Epigastric hernia

\section{INTRODUCTION}

Down's syndrome (TRISOMY 21) is the most common chromosomal disorder known. Characterized by up slanting of palpebral fissures, b/l epicanthic folds, flat nasal bridge, small ear and hypotonia and it is the most common genetic cause of intellectual disability. Down's syndrome is associated with multi-system congenital abnormalities include cardiac (44\%), digestive (6\%), musculoskeletal $(5 \%)$, urinary tract $(4 \%)$, respiratory $(2 \%) .{ }^{1}$ Anomalies of hepato-biliary-pancreatic system like intra-hepatic biliary atresia, annular pancreas, congenital porto-systemic shunt caused by patent ductus venosus, pancreatico-biliary maljunction are also reported. ${ }^{2}$ Down's syndrome is associated with increased incidence of cholelithiasis mainly seen in infants. Cholecystectomy in cases of down's syndrome is challenging procedure as anatomical variation in biliary system is anticipated in these patients. Moynihan hump also called caterpillar hump is an abnormal course of right hepatic artery in which tortuous right hepatic artery runs proximal and parallel to cystic duct. Incidence of caterpillar hump in general population varies from $1 \%$ to $13 \% .^{3}$ Congenital anterior abdominal wall hernia are seen rarely in Down's syndrome no cases have been reported.
This report aims to share a rare case of Cholelithiasis and epigastric hernia with multiple rectus sheath defects in Down's syndrome.

\section{CASE REPORT}

A 42 years male known case of Down's syndrome presented with complaints of pain upper abdomen from last 5 years. On evaluation ultrasonography abdomen s/o multiple calculi in gall bladder, normal CBD and normal GB wall thickness with 2 anterior abdominal wall defects in midline supra umbilical region with herniation of bowel loops and omental fat with defect measuring $\approx 24$ $\mathrm{mm}$ and $20 \mathrm{~mm}$.

Evaluated for cardiac anomalies 2D ECHO s/o Diastolic relaxation abnormality with LVEF $50 \%$. Patient is planned for elective laparoscopic cholecystectomy. Four trocars were placed as a routine cholecystectomy. Abdominal exploration revealed fatty liver (Figure 1) with Multiple rectus sheath defects in epigastric region (Figure 2). Subsequent anterior dissection of gall bladder revealed moynihan hump (an anatomical variation in course of right hepatic artery) (Figure 3), Cautious dissection of calot's triangle, course of right hepatic 
artery noticed and cystic artery lighted safely, cholecystectomy with primary repair of the rectus sheath defects performed. No post operative complications, patient discharged on POD 2.

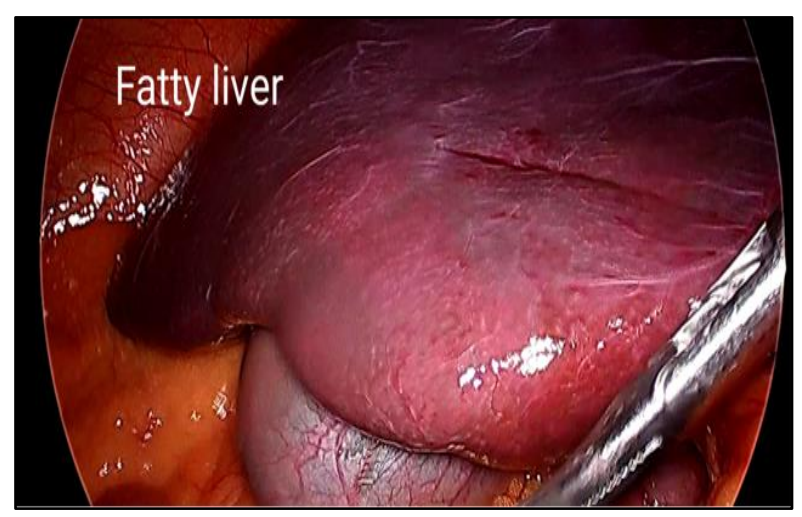

Figure 1: Fatty liver with distended gall bladder.

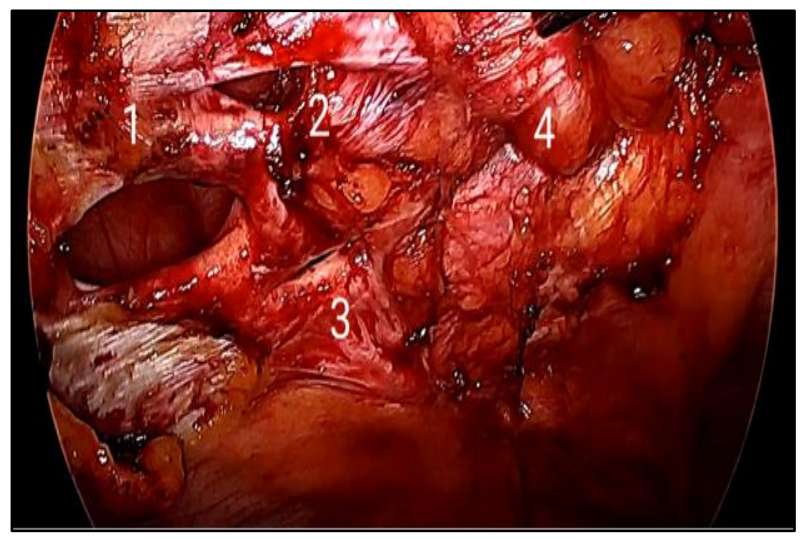

Figure 2: Multiple rectus sheath defects.

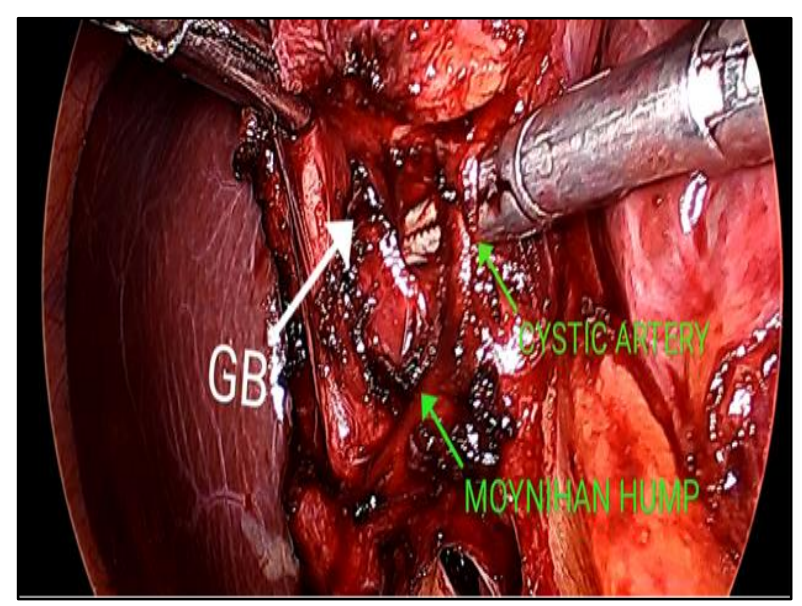

Figure 3: Abnormal course of right hepatic artery running in front of cystic duct.

\section{DISCUSSION}

Due to multi-system anomalies and intellectual disability anesthesia in cases of Down's syndrome is challenging and most of the operative cases of down's syndrome are neglected. Incidence of cholelithiasis in down's syndrome is $4.7 \% \mathrm{~m} / \mathrm{c}$ in infant, rare in adolescents. Most of the gall stones in down's syndrome are asymptomatic and most asymptomatic stones resolve spontaneously. ${ }^{4}$ Increased incidence of gall stones in down's syndrome is associated with risk factors like prematurity, hypercholesterolemia, hemolytic diseases, anatomical abnormalities of biliary tract, also some studies show decreased gall bladder motility increases risk of gall stones in Down's syndrome. ${ }^{5}$ Leptin resistance is also a cause of gall stones in Down's syndrome. ${ }^{6}$ Higher levels of leptin in their body leading to obesity and predisposing them to biliary stone formation. ${ }^{2}$ Non alcoholic fatty liver is seen in $82 \%$ of obese and $45 \%$ of non-obese down's syndrome patients. $^{7}$ Anomalies of biliary system associated with the down's syndromes are rare, countable cases are reported till now. Moynihan hump an anatomical variation in course of right hepatic artery is major cause of vascular injury and lap to open conversation of laparoscopic cholecystectomy, having anatomical knowledge about these anomalies and following basic principles of laparoscopic cholecystectomy are necessary to prevent complications.

Anomalies of musculoskeletal system like syndactyly, club foot, polydactyl, cataract, cleft palate are due to laxity in ligaments and low muscle tone associated with down's syndromes. These features also leads to hernias, diaphragmatic hernia is the most common hernia, recurrent chest infection in child with Down's syndrome one should suspect diaphragmatic hernia and evaluated and needs surgical repair. Anterior abdominal wall defects are rarely seen in Down's syndrome, these are mainly due to hypotonia of muscle. hypotonia may be due to collagen deficiency associated with chromosomal abnormalities. These hernias are usually asymptomatic, need surgical repair in symptomatic patients.

\section{CONCLUSION}

Cholelithiasis in Down's syndome is often asymptomatic or associated with non-specific symptoms (abdominal pain, vomiting, and fever). Complications including acute cholecystitis, cholangitis, biliary or gall bladder perforation, obstructive jaundice, biliary cirrhosis, and gall bladder carcinoma may occur. Clinicians should be aware of the increased risk of gallstones and their possible complications in Down's syndrome. Anatomical variations and abnormalities of biliary tract in case of down's syndrome are need to be studied more and only few cases have been reported till. Cholecystectomy in case of down's syndrome needs cautious dissection of calot's triangle and anatomical variations and anomalies should be ruled out intra-operatively. Collagen deficiency associated with Down's syndrome which results in hypotonicity muscle and results in hernia need to be studied. 
Funding: No funding sources

Conflict of interest: None declared

Ethical approval: Not required

\section{REFERENCES}

1. Stoll C, Dott B, Alembik Y, Roth MP. Associated congenital anomalies among cases with Down syndrome. Eur J Med Genet. 2015;58(12):674-80.

2. Puri P, Guiney EJ. Intrahepatic biliary atresia in Down's syndrome. J Pediatr Surg. 1975;10(3):4234.

3. Martín Pérez JA, Domínguez Rodríguez JA, De Alba Cruz I, Lara Valdés AJ, Sánchez Baltazar AL, Perna Lozada L. Moynihan's Lump as an unusual variant of right hepatic artery during a laparoscopic cholecystectomy approach. A case report. Int J Surg Case Rep. 2021;85:106221.

4. Toscana E, Trivellini V, Andrio G. Arch Dis Child. 2001;85(3):242-3.
5. Tasdemir HA, Cetinkaya MC, Caferpolat, Belet U, Kalayci AG, Akbar S. J Pediatr Gastroenterol Nutr. 2004;39(2):187-91.

6. Bertapelli F, Pitetti K, Agiovlasitis S, Guerra-Junior G. Overweight and obesity in children and adolescents with Down syndrome-prevalence, determinants, consequences, and interventions: A literature review. Res Dev Disabil. 2016;57:181-92.

7. A Ravel, C Mircher, A-S Rebillat, C Cieuta-walti, A Megarbane. Arch Pediatr. 2020;27(1):53-60.

8. Rescorda FJ. Cholelithiasis, cholecystitis, and common bile duct stones. Curr Opin Pediatr. 1997;9:276-82.

Cite this article as: Kankaria J, Madagond S.

Cholelithiasis with epigastric hernia in down's syndrome: a case report. Int Surg J 2022;9:699-701. 